\title{
EFFECT OF RAMADAN FASTING ON TEAR PROTEINS
}

\author{
Reyhaneh Sariri, Abdolali Varasteh, Reza Hassan Sajedi
}

University of Guilan, Faculty of Science, Rasht, Iran: Department of Biochemistry

\begin{abstract}
Summary: Muslims abstain from eating, drinking and smoking from dawn to sunset during the holy month of Ramadan. Prolonged fasting is thought to be among risk factors for many diseases, e.g., cardiovascular, gastrointestinal and various infectious diseases. It could also play a part in several eye diseases, including dry eye syndrome, glaucoma, and cataract. Toxic and oxidative effects due to increased concentrations of some biochemicals as a result of reduction in tear volume thought to play an important role in damaging ocular tissue. Human tear is an important biological fluid similar to blood in many aspects. Tear film is composed of three basic layers i.e. lipid, aqueous and mucin. The tear film covering the ocular surface presents a mechanical and antimicrobial barrier, and endures an optical refractive surface. The aim of this study was to analyze and compare tear protein of volunteers during fasting. Using two reliable analytical methods, i.e. electrophoresis and high performance liquid chromatography (HPLC), we compared tear protein content of sixty volunteers ( 35 males and 25 females, 23-27 years old) during fasting in holly month of Ramadan (FAST: $n=62$ ) and one month before Ramadan (CTRL: $n=60$ ). The results showed that some identified tear proteins decreased during fasting. On the other hand, the activity of some enzymes such as lysozyme, lactoferrin and alpha amylase also decreased in fasting samples. Electrophoresis results showed that tear protein patterns in FAST $(P<0.05)$ were different from those of CTRL. There were a few more protein peaks in the FAST group $(P<0.005)$ than in CTRL.
\end{abstract}

Key words: Tear proteins; Lysozyme; Fasting, HPLC; Electrophoresis

\section{Introduction}

\section{Tear film}

The eye is covered by a thin, fluid film that serves several functions. Tear film has fundamental roles in optical system, causes the lubrication, provides nutrients and growth factors for epithelium and serves as a barrier to the outside environment $(2,3)$. Stability and functionality of tear film plays an important role in ocular surface diseases. In previous studies, changes were found in tear protein patterns of smokers (12).

Structurally, tear film is composed of three layers: the superficial lipid layer, a middle aqueous layer and an inner mucus layer (11). Fig. 1 is a schematic representation of human eye showing the structure of tear film. In mammals, mocus layer is produced by goblet cells in the conjunctiva, the aqueous layer by lacrimal and other accessory glands and lipid layer by meibomian glands (19). In recent years, there has been increasing interest in exploring the proteome of the body fluids such as plasma (1), urine (17), cerebrospinal fluid (CSF) (22) and saliva (20).

Human tear film is an interesting and valuable body fluid in terms of diagnostic purposes. Despite its biochemical similarity to blood plasma, it is easily collectable with minimum trauma to the patient (18). A tiny drop of tear fluid could be used for diagnosis of certain eye diseases and even systemic diseases (23).

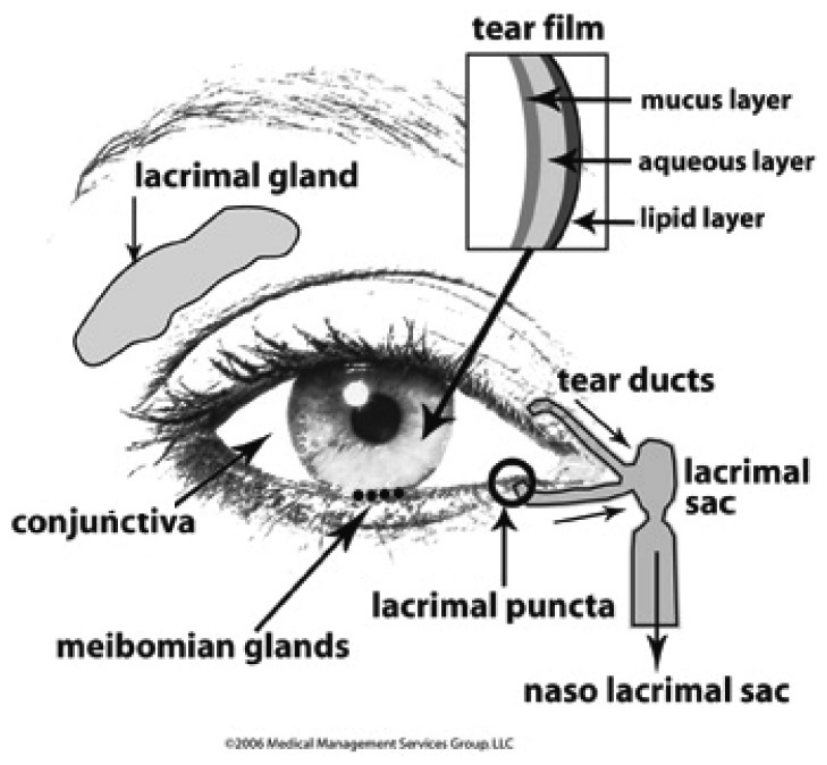

Fig. 1: Schematic representation of human eye and tear film structure. 
The aqueous phase of the tears contains a wide variety of organic and inorganic substances. In addition to the principal inorganic ions, as many as sixty proteins are present in the tears, together with a variety of biopolymers, glycoproteins, glucose and urea. Tab. 1 represents some of the most important tear proteins including lysozyme, lactoferrin, tear specific pre-albumin and secretory immunoglobulins (4).

Tab. 1: Average concentrations of some important tear proteins.

\begin{tabular}{|c|c|}
\hline Component & $\begin{array}{c}\text { Average Concentration } \\
(\mathrm{mg} / 100 \mathrm{ml})\end{array}$ \\
\hline Total protein & 751 \\
\hline Lysozyme & 236 \\
\hline Albumin & 130 \\
\hline Tear specific pre-albumin & 123 \\
\hline Lactoferrin & 184 \\
\hline Immunoglobulin A & 30 \\
\hline IgG & 12.6 \\
\hline IgM & 0.086 \\
\hline IgE & 0.01 \\
\hline
\end{tabular}

\section{Ramadan fasting}

One of the most important rules of Islam is that any healthy adult Muslim must refrain from eating, drinking, and smoking from sunrise to sunset during the holly month of Ramadan, the ninth month of Muslim calendar. Since this is a lunar calendar, the timing of this month changes each year and, therefore, the duration of restricted food and beverage intake can vary from ten to seventeen hours. Since the biochemistry of some biological fluids (such as blood and urine) has shown slight alterations due to fasting, it is expected that an extended strict fasting may influence tear quality.

\section{Materials and Methods}

\section{Materials}

Acetonitril, trifluoroacetic, acryl amide, sodium dodecyl sulphate (SDS), ammonium persulphate and sodium acetate were obtained from Sigma Chemical Company. polyvinylidene fluoride (PVDF) filters, HPLC materials and columns, and buffers were purchased from Merck representative in Iran. All other chemicals and solvents were of analytical grade and used as supplied by manufacturers.

\section{Tear sample collection}

Stimulated tear samples (using onion vapor), were obtained from 25 healthy volunteers, $20-25$ years old students in $50 \mu \mathrm{l}$ glass capillaries. Two samples were obtained from each subject, first sample was collected before beginning of Ramadan and the next one on $25^{\text {th }}$ day of Ramadan when all volunteers had been fasting for 25 days. Informed consent was obtained from all participants. Tear samples were transferred into $1.5 \mathrm{ml}$ Eppendorf and stored at $-18{ }^{\circ} \mathrm{C}$ until analysis.

\section{SDS-PAGE electrophoresis}

SDS-PAGE was performed using $4 \mu \mathrm{l}$ tear sample after boiling 3 minutes in water. The separating gel was $12 \%$ and stacking gel was $5 \%$. Electrophoresis analysis was performed under reducing conditions and the gels stained by Coomasie Brilliant Blue and silver nitrate.

\section{Zymogram}

Zymogram of alpha amylase was carried out with $8 \mu \mathrm{l}$ tear samples per well with $0.5 \%$ separating and $5 \%$ stacking gel. The solutions were triton X $1002.5 \%$ water, sodium acetate buffer $50 \mathrm{mM} \mathrm{pH} 6.0$, starch $1 \%$ in sodium acetate $50 \mathrm{mM}$ pH 6.0 and lugol solution.

\section{HPLC analysis}

Samples were analyzed using an HPLC apparatus from Knauer Company. The system contained a solvent organizer (k-1500), degasser (A-2015), mixing chamber, and pump (k-1001), and UV detector (k-2006).

Tear proteins were separated by $\mathrm{C} 18$ reverse-phase column (C18, 4.6 X $250 \mathrm{~mm}, 5 \mu \mathrm{m}, 300 \AA$ ) with the ability to separates proteins according to their hydrophobicity.

$20 \mu \mathrm{l}$ of tear sample were mixed with $40 \mu \mathrm{l}$ solvent (Acetonitril) and filtered by PVDF filter. The samples were injected using an injection loop of $50 \mu \mathrm{l}$. The run lasted for 100 minutes with the flow rate of $0.7 \mathrm{ml} / \mathrm{min}$. The eluted proteins were monitored at $280 \mathrm{~nm}$ and fractions corresponding to a particular protein peak were collected separately. Mobile phase A was acetonitril/water (5/95) in $0.01 \%$ trifluoroacetic acid and mobile phase B acetonitril/water $(95 / 5)$ in $0.01 \%$ TFA. HPLC conditions are given in Tab. 2.

Tab. 2: Compositions of mobile phases used in HPLC.

\begin{tabular}{|c|c|c|c|}
\hline Time $(\mathrm{min})$ & Flow rate & $\mathrm{A} \%$ & $\mathrm{~B} \%$ \\
\hline 0 & 0.7 & 95 & 5 \\
\hline 11 & 0.7 & 75 & 25 \\
\hline 35 & 0.7 & 60 & 40 \\
\hline 60 & 0.7 & 40 & 60 \\
\hline 90 & 0.7 & 15 & 85 \\
\hline 100 & 0.7 & 10 & 90 \\
\hline
\end{tabular}

\section{Results}

\section{SDS-PAGE electrophoresis}

At least 6 proteins were detected in both fasting and non-fasting tear samples using SDS-PAGE electrophoresis followed by silver staining (Fig. 2).

According to electrophoresis results, most of individual proteins slightly decreased in fasting compared to nonfasting samples. The extent of reduction was statistically 
Tab. 3.

\begin{tabular}{|l|c|c|c|}
\hline \multirow{2}{*}{ Proteins } & Control* $^{*}$ & Fasting* & Statistic \\
\cline { 2 - 4 } & $(\mathrm{mg} / 100 \mathrm{ml})$ & $(\mathrm{mg} / 100 \mathrm{ml})$ & difference \\
\hline Albumin & 132 & 112 & 1.5 \\
\hline Secretory Ig A & 31 & 27 & 0.6 \\
\hline Lactoferrin & 185 & 162 & 1.9 \\
\hline Lipocalin & 155 & 145 & 1.6 \\
\hline Lysozyme & 242 & 228 & 2.5 \\
\hline
\end{tabular}

*Mean values from 25 subjects.

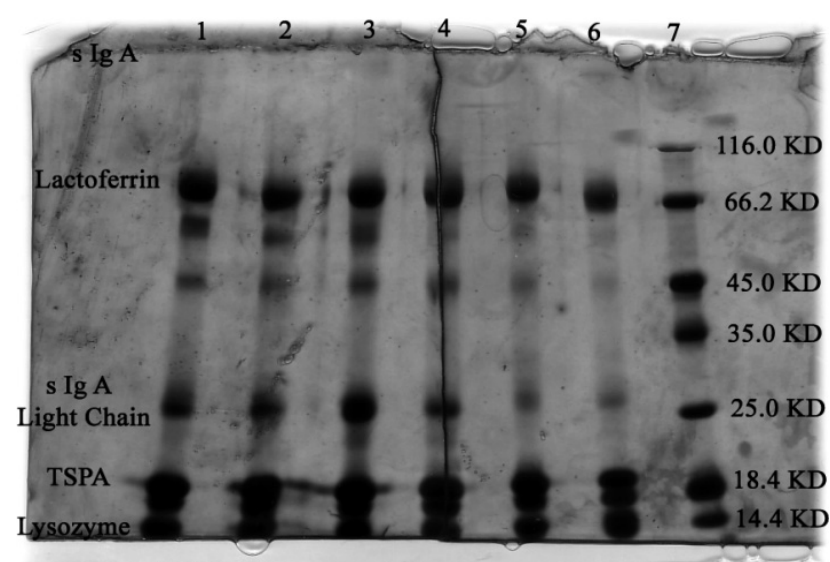

Control Fasting Control Fasting Control Fasting Size Marker

Fig. 2: SDS-PAGE electrophoresis of tear samples in fasting and non-fasting state.

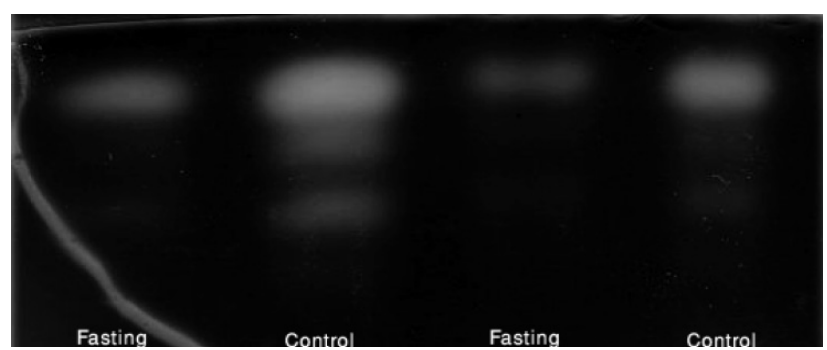

Fig. 3: Zymogram analysis of tear samples in fasting and non-fasting tear samples.

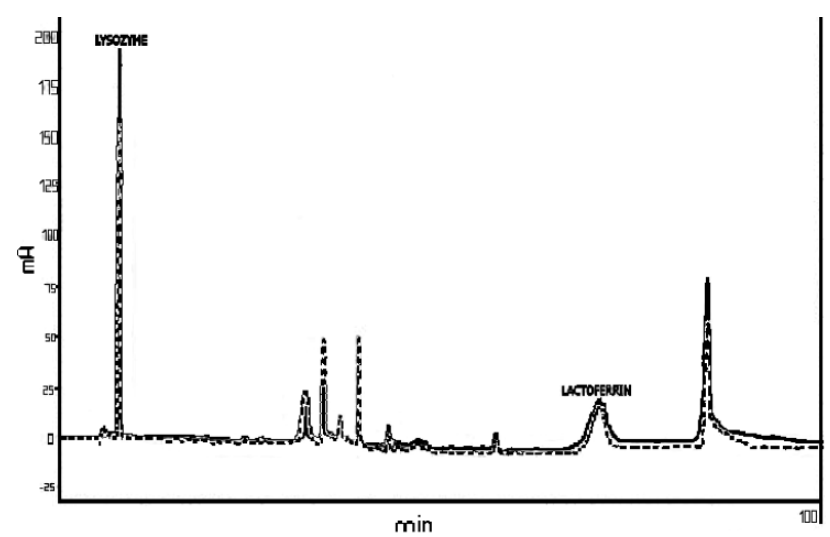

Fig. 4: HPLC analysis of tear samples in fasting (dotted) and non-fasting state (black). calculated using Total Lab software. The most detectable proteins in SDS-PAGE pattern were lactoferrin, albumin, secretory Ig A light chain, lipocalin and lysozyme (Fig. 2, Tab. 3).

\section{Zymogram}

Zymogram of alpha amylase showed three bonds indicating the possible presence of three isoenzymes (Fig. 3). It is also clear from this Fig. that the quantity of the enzyme has decreased in fasting samples.

\section{HPLC analysis}

In HPLC chromatograms of tear samples at least 11 peaks were detected. Among these, only two peaks could be identified in our laboratory: lactoferrin and lysozyme. HPLC chromatogram presented in Fig. 4 strongly supports the results obtained by electrophoresis, i.e. a reduction in concentration of some proteins (lysozyme and lactoferrin). However, some bands appeared in the tears of fasting individual that were not detectable in non-fasting samples.

\section{Statistical procedure}

For each electrophoretic lane a data vector was created, and the $\mathrm{Rf}$ range (i.e., $\mathrm{Rf}=0$ through $\mathrm{Rf}=1$ ) was divided into 60 classes. Every variable of the data vector thus represents $1 / 60$ of the complete $\mathrm{Rf}$ range. Calculations on all peaks of each electrophoretic lane determined into which particular $\mathrm{Rf}$ class a peak fell. Each peak volume was added to the corresponding variable of its $\mathrm{Rf}$ class in the data vector of the electrophoretic lane. From these data vectors, a discriminant multivariate analysis was performed. This analysis not only tests the zero hypothesis that mean data vectors of the different groups derive from a normally distributed multivariate population, but also it shows which groups are statistically different. Thus, discriminant function analysis can be used to determine which variables (Rf ranges) caused the mean value comparison to become significant, or which variables can discriminate between groups. Additionally, the analysis allows classification of electrophoretic patterns; it can be used to test whether an individual protein pattern is similar to the pattern of a particular known group, or to which of several group patterns it shows the greatest similarity. The statistical calculations were performed by Statistica (Ver 6, Statsoft, Tulsa, Okla. USA).

\section{Discussion}

Identification, determination of characteristics and measurement the quantity of tear proteins by analytical techniques is very important in understanding the physiological properties of tear as well as using tear samples as a diagnostic possibility for clinical applications. Different ways of stimulation can affect the concentrations of biochemicals in tears and rate of their release. In this study we used 
glass capillary for collection of tear. This method of tear collection has great accuracy, because soaking a filter paper, for example, may induce some alternations in various tear components.

Religious fasting necessitates abstinence of food intake during daytime for about 10-17 hours, depending on seasonal factors. In this study, we assessed changes in tear proteins of fasting individuals.

Most of research works in this regard deals with blood, while saliva and tear have received less attention. Considering that collection of tear and saliva sample is easier, it was decided to assess proteins in tear samples in fasting and non-fasting states. The results of this study can lead to the correlations between blood and tear biochemistry and determine if tear samples could be used as a diagnostic tool for various disorders of human body including eye disorders. The results are also very important to understand the mechanisms involved during starvation.

Electrophoresis pattern of tear samples in Fig. 2 indicate that some tear proteins are decreased in fasting state. However, total tear proteins showed an increase using Lawry protein assay (the results not included here). In most cases, zymogram of alpha amylase showed three bonds referring to at least three isoenzymes. Fig. 3 shows that the concentration of two isozymes is lower in fasting state while only one isozyme shows almost un-altered concentrations in both states. A similar situation has been demonstrated in the case of pyruvate dehydrogenase kinase isozymes. It has been reported that isozyme 4 (PDHK-4) is decreased in muscle, during prolonged fasting (6). HPLC analysis of tear samples shown in Fig. 4 states that most of proteins have been decreased in fasting state. The electrograms of lactoferrin and lysozyme are indicated in this figure.

It is known that in short-term starvation blood glucose is the first metabolite that is used and its concentration diminishes. It seems likely that low concentration of glucose is a positive sign for sympathetic nervous system activity. Fasting has been shown to have a profound effect on sympathetic nervous system, best characterized by an increase in adrenergic stimulation and reduced tissue sensitivity to catecholamines $(8,9,15,21)$. Secretion of protein in lacrimal gland is based on nervous regulations. So when the sympathetic nervous system is more active in fasting state, secretion of protein is decreased be deactivation of protein kinase $\mathrm{C} \alpha$ and $\delta$.

Tear protein pattern have been used as a diagnostic tool by other researchers (5). A significant difference in tear protein patterns between patients suffering from dry eye and healthy volunteers has demonstrated by one-dimensional electrophoretic separation of tear proteins (10). In further studies, differences in tear protein patterns of diabetic patients have been demonstrated by two-dimensional gel electrophoresis (13). In other studies, electrophoretic characteristics of different tear proteins have been investigated $(7,16)$.
Furthermore, it could be demonstrated that analysis of tear proteins, and the multivariate approach including all peaks in the analysis, can be helpful in dry-eye disease diagnosis or follow-up (14). However, some problems remain before routine clinical use of these methods. Reproducibility must be investigated in further studies, and variation of tear protein patterns even in the same subject must be considered. Nevertheless, analysis of tear proteins is suitable for detecting changes in complex patterns, e.g., during development of diseases or other circumstances.

Our study investigated the effect of one month fasting on tear proteins. There is no doubt about the influence of fasting on many systemic diseases and even on many eye diseases. However, little is known about the influence of fasting on tears. In the present study, we found alterations in the protein content of tear film during one month fasting.

\section{Acknowledgement}

The authors wish to thank Dr Alireza Aliakbar, Dr Davoud Bakhshi, and Mr Javad Feizi for their technical assistance in HPLC analysis.

\section{References}

1. Anderson NL and Anderson NG. The human plasma proteome: history, character, and diagnostic prospects. Mol Cell proteomics 2002;1: 845-67.

2. Dilly PN. Structure and function of the tear film. Adv Exp Med Biol 1994;350:239-47.

3. Fleiszig SM, Mc Namara NA and Evans DJ. The tear film and defense against infection. Adv Exp Med Biol 2002;506:523-30.

4. Gachon AM, Verrelle P, Betail G and Dastugue B. Immunological and Electrophoretic Studies of Human Tear Proteins. Exp Eye Res 1979; 29: 539-553.

5. Grus FH, Augustin AJ, Evangelou NG, Toth-Sagi K. Analysis of tear-protein patterns as a diagnostic tool for the detection of dry-eyes in diabetic and non-diabetic dry-eye patients. Eur J Ophthalmol 1998;8(2):90-97.

6. Jeoung NH, Wu P, Joshi MA, Jaskiewicz J, Bock CB, De Paoli-Roach AA and Harris RA. Role of pyruvate dehydrogenase kinase isoenzyme 4 (PDHK4) in glucose homoeostasis during starvation. Biochem J 2006;397:417-25.

7. Kuizenga, A, van Haeringen NJ and Kijlstra A. SDS-Minigel electrophoresis of human tears. Effect of sample treatment on protein patterns. Invest Ophthalmol Vis Sci, 1991; 32:381-386.

8. Landsberg LL, and Young JB. Fasting, feeding and regulation of the sympathetic nervous system. New Engl J Med 1987; 298:1295-30.

9. Leiter LA, Grose M, Yale JF, and Marliss EB. Catecholamine responses to hypocaloric diets and fasting in obese human subjects. Am J Physiol, 1984; 247:190-97.

10. Ohashi Y, Ishida R and Kojima T, Abnormal protein profiles in tears with dry eye syndrome, Am J Ophthalmol 2003;136:291-299.

11. Ohashi Y, Dogru M, and Tsubota K. Laboratory findings in tear fluid analysis. Clinica Chimica Acta 2006; 369:17-28.

12. Sariri R, Arasteh A, and Mahmoodian J. Heavy smoking and tear proteins. Asian Journal of Chemistry 2006;18:15-19.

13. Sariri R, Khamedi A. Variations in electrophoretic tear protein pattern. J Chrom A 2007;1161:64-6.

14. Sack RA, Bogart Bi, Beaton A, Sathe S, Lew, G. Diurnal variations in tear glycoproteins: evidence for an epithelial origin for the major non-reducible $450 \mathrm{kDa}$ sialoglycoprotein(s). Curr Eye Res 1997; 16:577-88.

15. Schaefer S, Wang LF, Vliet A van der, Hristova M, Vulliet PR and Fan SD Fasting Limits Norepinephrine Release with Myocardial Ischemia and Reperfusion. Cardiovascular Drugs and Therapy. 1999;13:399-405.

16. Snyder C and Fullard RJ. Clinical profiles of non dry eye patients and correlations with tear protein levels. Inter Ophtalmol 1991;15:383-9.

17. Thongboonkerd V, Mc leish KR, Arthur JM and Klein JB. Proteomic analysis of normal human urinary proteins isolated by acetone precipitation or ultracentrifugation. Kidney Int. 2002;62:1461-9. 
18. Van Haeringen NJ, Clinical biochemistry of tears. Survey of Ophthalmology 26(2), 1981, 84-96

19. Walcott B. The lacrimal gland and its veil of tears. News Physiol Sci 1998; 13:97-103.

20. Wilmarth PA, Riviere MA, Rustvold DL, Lauten JD, Madden TE, and David LL.

Two-dimensional liquid chromatography study of the human whole saliva proteome. J. Proteome Res 2004; 3:1017-23.
21. Young JB, and Landsberg L. Suppression of sympathetic nervous system during fasting. Am J Physiol 1981;240:314-19.

22. Yuan $X$ and Desiderio DM. Proteomics analysis of human cerebrospinal fluid. J Chromatogr B Analyt Technol Biomed Life Sci 2005; 815:179-89.

23. Zhou L, Beuerman RW, Foo Y, Liu S, Ang LPK, and Tan DTH. Characterisation of human tear proteins using high resolution mass spectrometry. Ann Acad Med Singapore 2006;35:400-8

Received: 26/06/2009.

Accepted in revised form: 20/05/2010.

\section{Corresponding author:}

Reyhaneh Sariri, Department of Biochemistry, Faculty of Science University of Guilan, Namjoo Street, Rasht, Iran; e-mail: sariri@guilan.ac.ir 